\title{
Feeding of krill around South Georgia. II. Relations between feeding activity, environment and vertical distribution
}

\author{
D. J. Morris, I. Everson, C. Ricketts and P. Ward
}

British Antarctic Survey, Natural Environment Research Council, High Cross, Madingley Road, Cambridge CB3 0ET, United Kingdom

\begin{abstract}
Relations between a model of the feeding activity of Euphausia superba, the oceanic environment and the vertical distribution of krill around South Georgia are described. Krill with full alimentary tracts occur both above and below the thermocline, over a 20 -fold range of chlorophyll concentration. Changes in chlorophyll concentration, temperature, salinity and nutrients which occur down the water column appear to have no effect upon the feeding activity of krill. As the energy requirements of krill can be met with known filtration rates over the range of chlorophyll concentrations encountered, this study suggests that krill adjust their filtration rate to compensate for wide changes in chlorophyll concentration and feed throughout the water column. We cannot, however, exclude the possibility that krill from all depths could have fed in the cod-end of the net in the surface layer.
\end{abstract}

An intensive 6 d study of Euphausia superba Dana off South Georgia has allowed the construction of a model for feeding activity (Morris and Ricketts, 1984). The extensive statistical analysis used in developing the model permitted a simplification of the complex interactions between environmental factors (depth and time of day) and the fullness of stomach, hepatopancreas and gut. In this simplified model, time of day only affected stomach fullness and stomach fullness affected both hepatopancreas fullness and gut fullness independently. There was no effect of depth upon the fullness of the stomach, hepatopancreas or gut. In this paper we examine the interrelations between this model, the oceanic environment and the vertical distribution of krill.

Materials and methods. Location of the patch studied, sampling regime, methods of analysis of the feeding state of Euphausia superba and the measurement of chlorophyll levels are described in Morris and Ricketts (1984). Salinity, temperature and depth (STD) were measured using a Plessey salinity-temperature profiler with a General Oceanics water bottle rosette system which provided water bottle samples at stan- dard depths of $3,10,30,50,70,100$ and $150 \mathrm{~m}$. Nitrite and nitrate, phosphate and silicate levels of the water bottle samples were determined using a multi-channel auto-analyser and analysis techniques from Folkard (1978).

A series of 12 STD and chlorophyll profiles was made on the net haul track $\left(53^{\circ} 54^{\prime} \mathrm{S}, 36^{\circ} 18^{\prime} \mathrm{W}\right.$ to $53^{\circ} 56^{\prime} \mathrm{S}, 36^{\circ} 11^{\prime} \mathrm{W}$ ) during the 6 -d study. In addition, 4 STD profiles were made after the study period in a grid around the haul track $\left(53^{\circ} 50^{\prime} \mathrm{S}, 36^{\circ} 20^{\prime} \mathrm{W} ; 54^{\circ} \mathrm{S}\right.$, $\left.36^{\circ} 20^{\prime} \mathrm{W} ; 54^{\circ} \mathrm{S}, 36^{\circ} 10^{\prime} \mathrm{W} ; 53^{\circ} 50^{\prime} \mathrm{S}, 36^{\circ} 10^{\prime} \mathrm{W}\right)$. These 4 stations provided the chemical characteristics of the water encountered by the krill during the study period.

The average density of krill in the water for each time/depth combination was estimated from the total volume of krill caught (converted to a number of krill $\mathrm{m}^{-3}$ on the basis of direct measurement that $4,000 \mathrm{krill}$ occupied one litre) and the average amount of water filtered by the gear obtained from calibrated flowmeters. The vertical distribution of the krill swarms below the surface layer was obtained using a Simrad EKS-120 echosounder.

In order to examine the relations between feeding state, as described by Morris an Ricketts (1984), and the physico-chemical environment it is necessary to remove those physiological factors which may influence feeding activity. Because the process of moulting entails the emptying of the alimentary tract (Mauchline and Fisher, 1969) we have excluded from this analysis those krill which could have been involved in moulting $(30 \%)$, on the basis of either hardness of exoskeleton or feeding state (Morris, in prep).

Results. The density of Euphausia superba (derived from net hauls) was highest above the thermocline, particularly at the surface during darkness (Table 1). It is unknown whether krill at the surface at night were in swarms or dispersed. Krill were present below the thermocline, but the density was lower. Krill above the 
Table 1. Euphausia superba. Average number of specimens $\mathrm{m}^{-3}$ as a function of depth and time of day (pooled by day). Data obtained from net hauls

\begin{tabular}{|lccccccc|}
\hline \multicolumn{1}{|c|}{$\begin{array}{c}\text { Depth range } \\
(\mathrm{m})\end{array}$} & $08-12$ & $12-16$ & $16-20$ & $20-24$ & $24-04$ & $04-08$ \\
\hline $\begin{array}{l}\text { Surface } \\
0-3\end{array}$ & 0.0 & 0.0 & 0.0 & 29.2 & 145.5 & 0.0 \\
$\begin{array}{l}\text { Above thermocline } \\
10-50\end{array}$ & 2.1 & 5.8 & 3.0 & 0.1 & 2.0 & 8.2 \\
$\begin{array}{l}\text { Below thermocline } \\
70-100 \\
\text { Below 100 m }\end{array}$ & 0.1 & 0.2 & 0.2 & 0.1 & 0.7 & 1.5 \\
$100-150$ & 0.0 & 0.0 & 0.2 & 0.2 & 1.3 & 0.8 \\
\hline
\end{tabular}

thermocline but below the surface layer were aggregated into swarms, whereas those below were not. In addition, the swarms occurred nearer the surface at night than during the day (Fig. 1).

The surface temperature of approximately $2.5^{\circ} \mathrm{C}$ remained constant to $30 \mathrm{~m}$ (Fig. 2); below this it decreased to $0{ }^{\circ} \mathrm{C}$ at $70 \mathrm{~m}$, and then increased to approximately $1{ }^{\circ} \mathrm{C}$ at $150 \mathrm{~m}$. Salinity (Fig. 2) increased below the thermocline from less than $33.9 \mathrm{ppt}$ to more than $34.2 \mathrm{ppt}$. Chlorophyll $a$ and phaeopigment were distributed uniformly from the surface to $30 \mathrm{~m}$ (Fig. 2) at approximately $1 \mu \mathrm{g} \mathrm{l}^{-1}$. Below that, the amount of plant pigment decreased to less than $0.2 \mu \mathrm{g} \mathrm{l}^{-1}$ at $70 \mathrm{~m}$ and $0.05 \mu \mathrm{g} \mathrm{l}^{-1}$ at a depth of $150 \mathrm{~m}$. The proportion of phaeopigment as a function of total plant pigment was approximately $10 \%$ above $30 \mathrm{~m}$ and greater than $40 \%$ below $70 \mathrm{~m}$. The increase in variability of all profiles at $50 \mathrm{~m}$ is a result of variation in the depth of the thermocline during the study period.

Water chemistry data for the 4 STD stations around the haul track are presented in Fig. 3. All 3 sets of nutrient profiles show low levels above the thermocline with increasing concentrations down to $150 \mathrm{~m}$.

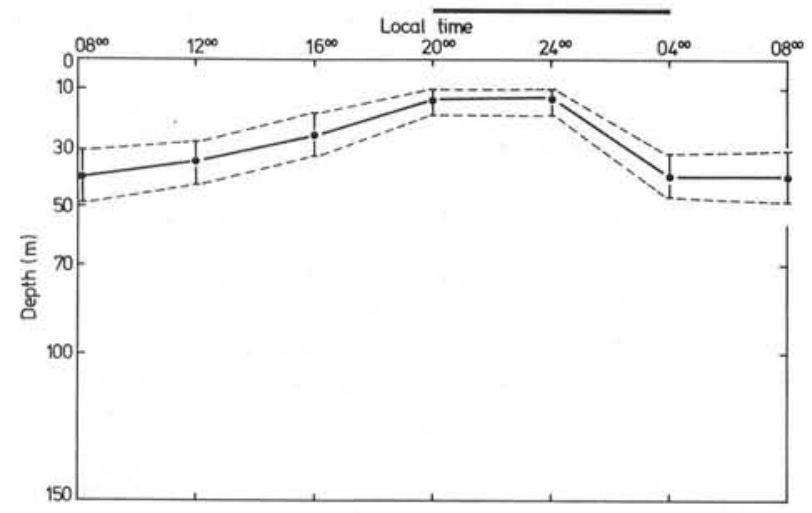

Fig. 1. Euphausia superba. Mean depth and mean upper and lower limits of krill swarms as a function of time of day (pooled by day). Bar: darkness
All 4 stations are essentially similar and any differences reflect the complex nature of the water currents off South Georgia (Heywood, pers. comm.).

Discussion. The model of krill feeding activity developed by Morris and Ricketts (1984) describes the variation of stomach, hepatopancreas and gut fullness in relation to depth and time of day. Here we discuss the ecological implications of the relations between environment, distribution, behaviour and feeding activity of Euphausia superba. There was little temporal variation in either oceanic environment, distribution, behaviour or feeding activity of krill. However, there were considerable changes in the environment particularly chlorophyll concentration - and the behaviour of krill with depth. These were not reflected in changes in the fullness of the alimentary tract (Morris and Ricketts, 1984). The absence of changes in feeding activity with depth contrasts with the numerous proposed links between feeding, vertical migration and food availability (Pavlov, 1969; Gubsch, 1979; Kalinowski and Witek, 1980; Antezana et al., 1982; Morris et al., 1983).

This absence of a depth effect upon the level of feeding activity implies that feeding activity (or ingestion) is not affected by the 20 -fold decrease in plant pigment between 0 and $150 \mathrm{~m}$. Neither is feeding activity affected by the occurrence of krill in swarms or in the dispersed condition, nor is it affected by the decrease in temperature or the increase in salinity or nutrients with depth. Previous studies also indicate that the density of krill may affect filtration rates (Morris et al., 1983) although feeding occurs both in and out of swarms (Antezana and Ray, 1984), and that ambient levels of chlorophyll do affect filtration rates in the laboratory (Antezana et al., 1982). This study of feeding activity in the field supports these conclusions and suggests that a constant ingestion rate is maintained by krill adjusting their filtration rate to a wide range of ambient concentrations of food.

Clarke and Morris (1983) indicate that krill around South Georgia of the size under consideration (approximately $30 \mathrm{~mm}$ ) will require $300 \mathrm{ng}$ chlorophyll $\mathrm{h}^{-1}$ to sustain metabolism and support growth. At an ambient chlorophyll concentration of $1 \mu \mathrm{g} \mathrm{l}^{-1}$ (surface) this would require the filtration of a minimum of $0.33 \mathrm{l}^{-1}$. At an ambient chlorophyll concentration of $0.05 \mu \mathrm{g} \mathrm{l}^{-1}$ $(150 \mathrm{~m})$ this rises to $6.7 \mathrm{l} \mathrm{h}^{-1}$. These rates are well within the range found by Morris (in press) even when corrections are applied for the retention efficiency of the filtration mechanism (McClatchie and Boyd, 1983; Kils, 1984). Thus the available experimental evidence shows that krill could maintain a constant ingestion rate in the face of large differences in ambient chlorophyll. The data from this study therefore suggest that krill adjust their filtration rate to compensate for 
Fig. 2. Environmental profiles (mean $\pm \mathrm{SD}$ ) for 12 STD stations on the haul track

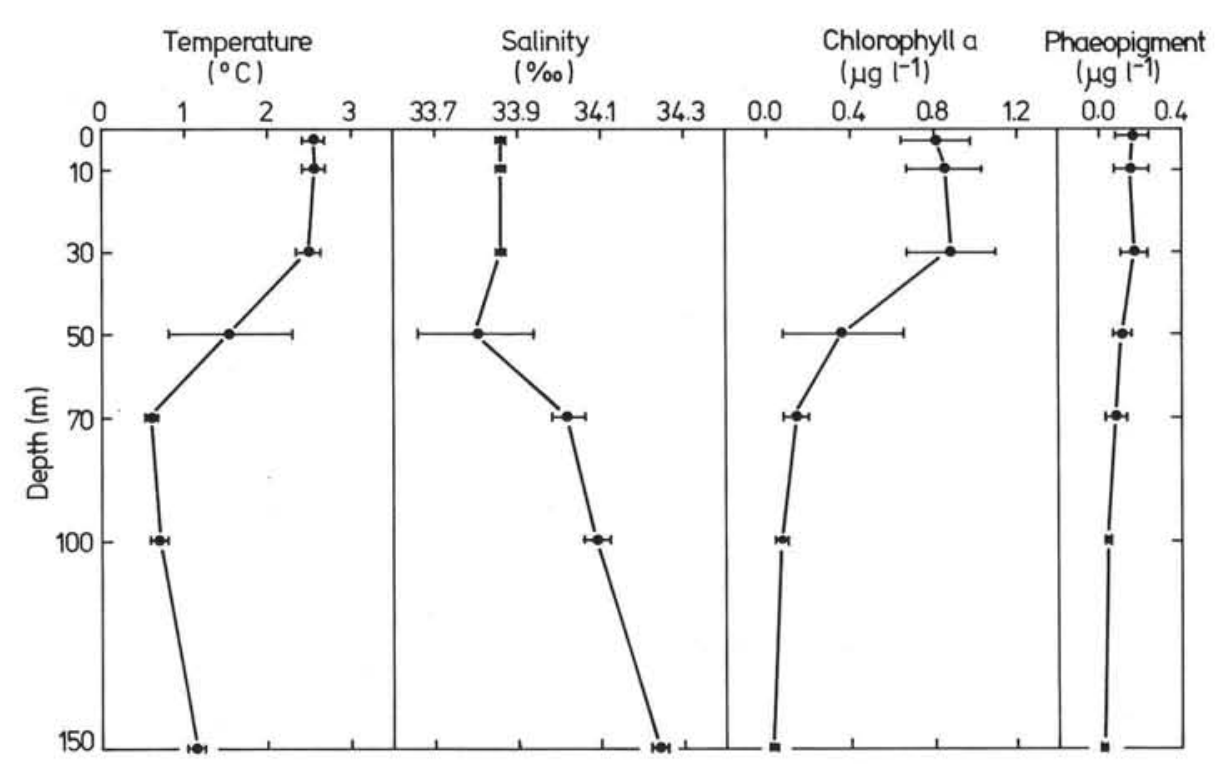

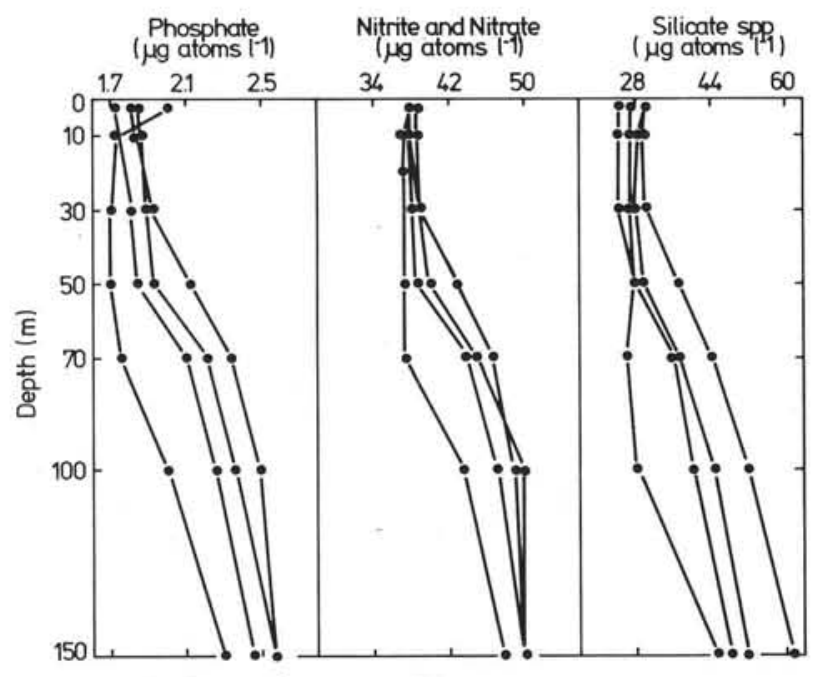

Fig. 3. Nutrient profiles for the 4 STD stations around the haul track

wide changes in chlorophyll concentration, and feed throughout the water column.

Because this conclusion conflicts with the proposed strong links between feeding activity, swarming and vertical migration of krill we wish to suggest another possible explanation of our results. An ingestion rate of $300 \mathrm{ng}$ chlorophyll h $\mathrm{h}^{-1}$ (Clarke and Morris, 1983) and an internal plant pigment content of $35 \mathrm{ng}$ (Morris and Ricketts, 1984) implies that the entire contents of the stomach and hepatopancreas are turned over approximately once every $7 \mathrm{~min}$. All krill spent at least $20 \mathrm{~min}$ in the net above the thermocline (high chlorophyll concentration), and feeding in the cod end of the net could have resulted in all krill filling their tracts, regardless of the depths from which they were caught. However, the occurrence of such feeding activity is unproven and seems unlikely in view of the physical confinement, high krill densities and relatively low water flow through the cod-end of a closed RMT 8 net.

This study shows that Euphausia superba maintains a relatively constant amount of plant pigment in stomach and hepatopancreas, despite large changes in local chlorophyll concentration. It also indicates that the turnover rate of chlorophyll in stomach and hepatopancreas is of the order of minutes rather than hours. In future studies, the sampling interval should be of the order of the turnover time of the digestive system. Until such sampling techniques can be applied, the interpretation of both field and laboratory studies of krill feeding remain open to question.

Acknowledgements. We thank R. B. Heywood, T. M. Whittaker, M. Whitehouse for making available their unpublished data.

\section{LITERATURE CITED}

Antezana, T., Ray, K., Melo, C. (1982). Trophic behaviour of Euphausia superba Dana in laboratory conditions. Polar Biol. 1: 77-82

Antezana, T., Ray, K. (1984). Feeding of Euphausia superba in a swarm north of Elephant Island. J. Crust. Biol., Spec. No. $26-38$

Clarke, A., Morris, D. J. (1983). Towards an energy budget for krill: the physiology and biochemistry of Euphausia superba Dana. Polar Biol. 2: 69-86

Folkard, A. R. (1978). Automatic analysis of seawater nutrients. M.A.F.F. Fish. Res. Tech. Rep. No. 46: 1-23

Gubsch, G. (1979). Investigations on krill Euphausia superba Dana off South Orkneys and South Shetlands in 1979. ICES CM L 34: 12

Kalinowski, J., Witek, Z. (1980). Diurnal vertical distribution and migration of krill swarms in the western Antarctic. ICES CM L 49: 1-12

Kils, U. (1984). Swimming and feeding of Antarctic krill, Euphausia superba - some outstanding energetics and 
dynamics, some unique morphological details. In: Schnack, S. (ed.) On the biology of krill Euphausia superba. Ber. Polarforsch. 4: 130-155

Mauchline, J., Fisher, L. R. (1969). The biology of euphausiids. Adv. mar. Biol. 7, 1-454

McClatchie, S., Boyd, C. M. (1983). Morphological study of sieve efficiencies and mandibular surfaces in the Antarctic krill, Euphausia superba. Can. J. Fish. aquat. Sci. 40: 955-967

Morris, D. J. (in press). Filtration rates of Euphausia superba: under or overestimates? J. Crust. Biol., Spec. No.
Morris, D. J., Ricketts, C. (1984). Feeding of krill around South Georgia I. A model of feeding activity in relation to depth and time of day. Mar. Ecol. Prog. Ser. 16: 1-7

Morris, D. J., Ward, P., Clarke, A. (1983). Some aspects of feeding in the Antarctic krill Euphausia superba. Polar Biol. 2: 21-26

Pavlov, V. Ya. (1969). The feeding of krill and some features of its behaviour. Trudy. vses. nauchno-issled. Inst. morsk. ryb. khoz. Okeanogr. 66: 207-222

Accepted for printing on July 21, 1984 